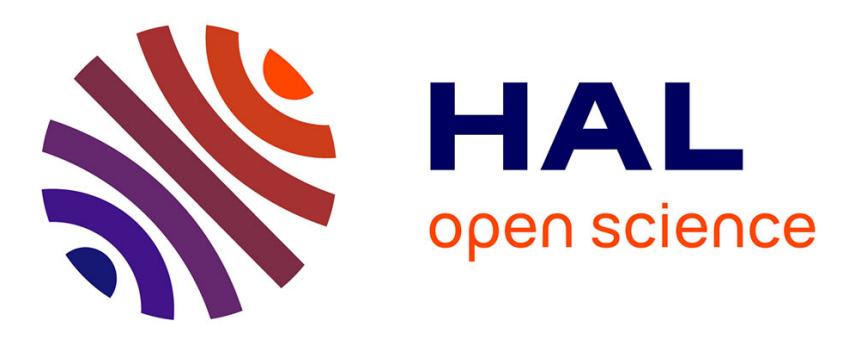

\title{
Experimental study and modeling of the behavior of partially saturated asphalt concrete under freezing condition
}

van Thang Vu, Olivier Chupin, Jean Michel Piau, Ferhat Hammoum, Stéphane Bouron

\section{To cite this version:}

van Thang Vu, Olivier Chupin, Jean Michel Piau, Ferhat Hammoum, Stéphane Bouron. Experimental study and modeling of the behavior of partially saturated asphalt concrete under freezing condition. Construction and Building Materials, 2018, 163, pp.169-178. 10.1016/j.conbuildmat.2017.12.070 . hal-01731346

\author{
HAL Id: hal-01731346 \\ https://hal.science/hal-01731346
}

Submitted on 8 Jul 2021

HAL is a multi-disciplinary open access archive for the deposit and dissemination of scientific research documents, whether they are published or not. The documents may come from teaching and research institutions in France or abroad, or from public or private research centers.
L'archive ouverte pluridisciplinaire HAL, est destinée au dépôt et à la diffusion de documents scientifiques de niveau recherche, publiés ou non, émanant des établissements d'enseignement et de recherche français ou étrangers, des laboratoires publics ou privés. 


\section{Experimental study and modeling of the behavior of partially \\ 2 saturated asphalt concrete under freezing condition}

3 Van Thang VU, Olivier CHUPIN, Jean-Michel PIAU, Ferhat HAMMOUM, Stéphane BOURON

IFSTTAR, MAST, F-44344 Bouguenais, France

6 ABSTRACT

7 Asphalt pavement damaging characterized by series of potholes was recently observed in

8 France and Northern Europe. This type of pavement distress surprisingly occurred in short

9 time laps over large distances during winters and after rainfalls had taken place. Based on these observations, a specific mechanism is suspected to be responsible for such disorders. This mechanism is believed to be related to the behavior under freezing conditions of asphalt concrete (AC) partially saturated with water, which is the focus of the present research. To investigate this behavior two types of experimental test are carried out in the laboratory. One test is performed under free stress condition while the other test is subjected to restrained strain. The experimental results from these two tests show the development of swelling strain and induced stress in the saturated asphalt specimens, respectively. These two effects are attributed to the phase change of pore water from liquid to solid. A constitutive law taking into account viscoelasticity of $\mathrm{AC}$, thermal expansion and swelling induced by frost is elaborated. This law is implemented in a numerical program and validated against the experimental results.

21 Keywords: saturated asphalt concrete, freezing, swelling, viscoelasticity, constitutive law. 


\section{INTRODUCTION}

This research was motivated by field feedbacks showing the apparition of series of potholes taking place in some asphalt pavements in France and other Northern Europe countries. Such degradation occurred almost simultaneously (typically in half a day) over some important part of road sections and under particular weather circumstances combining cold temperatures and rainfall events. Early investigations of these disorders [1][2] have pointed out that a specific mechanism could be at the origin of the problem and that this mechanism was likely related to the mechanical behavior of asphalt concrete (AC) partially saturated with water when subjected to freezing. Traffic and initial damage might represent propitious or aggravating factors to this deterioration mechanism.

The mechanical response of partially saturated AC specimens undergoing freezing then started to be studied in the laboratory [3][4]. Experimental tests were performed at the timescale of one (or a few) frost/thaw cycle(s) focusing on the strain evolution during freezing. Results from these studies show that large swelling strain develops in the AC sample during cooling starting at the time at which temperature in the sample reaches some negative value. This swelling strain is attributed to freezing of the pore water occluded in the AC specimen.

In this paper, we present additional tests performed on saturated AC to quantify the level of strain but also of stress that can originate from freezing of pore water. The objective is then to use these tests to elaborate a constitutive law dedicated to saturated AC. Two tests are considered. One is run considering traction free boundary condition that let the sample deform freely. The other test is performed under restrained strain and makes thermal stress occur in the sample. The tests performed clearly show the impact of the pore water phase change on the experimental data. 
It is only recently and following feedbacks from the field that the combined effects of moisture and frost is considered as possibly leading to a frank mechanism of pavement structure deterioration, which often results from fatigue process. This mechanism is not well understood yet and for this reason is investigated in the present work.

Note that in the past, moisture susceptibility and moisture damage of $\mathrm{AC}$ was studied putting into evidence its impact on the long term on stripping, raveling, shelling and hydraulic scour $[5][6][7][8]$. On the other hand, the impact of frost on pavements was also studied in the laboratory but rather from the sight of the long-term effect of repeated cycles [9][10]. Interestingly, the results from this research shows that the internal structure of AC is modified according to the number of cycles applied, resulting in an increase of void ratio and permeability [11][12] and a decrease of the AC stiffness [13]. All these effects can contribute to weaken AC pavements but cannot explain the sudden and simultaneous onset of potholes.

This paper is divided into three main sections. First we present the experimental testing of saturated AC materials. Based on the test results, the development of a constitutive law as well as its implementation in a numerical program is presented in a second part. Finally, this law is validated against experimental data.

\section{EXPERIMENTAL TESTING}

Two tests are considered in this section to investigate the behavior of partially saturated AC under freezing. The first test performed according to traction free boundary condition is denoted CTFS which is the acronym for Cooling Test in Free Stress condition. This test is used to evaluate swelling strain that develops in saturated $\mathrm{AC}$ under freezing condition. The associated dual variable is the freezing-induced stress which is quantified by means of TSRST which stands for Thermal Stress Restrained of Specimen Test. AC samples are subject to restrained strain during this test.

In this section, the AC materials used in the present study and the experimental procedures applicable to each tests are detailed prior to the experimental results are commented. 
The asphalt mixture used in this study is designed according to the French formulation method [14] and is denoted BBSG with a nominal aggregate size of $0 / 14 \mathrm{~mm}$. Its gradation curve is shown in figure 1 . A bitumen classified 35/50 with a content of 4.45 ppc was used.

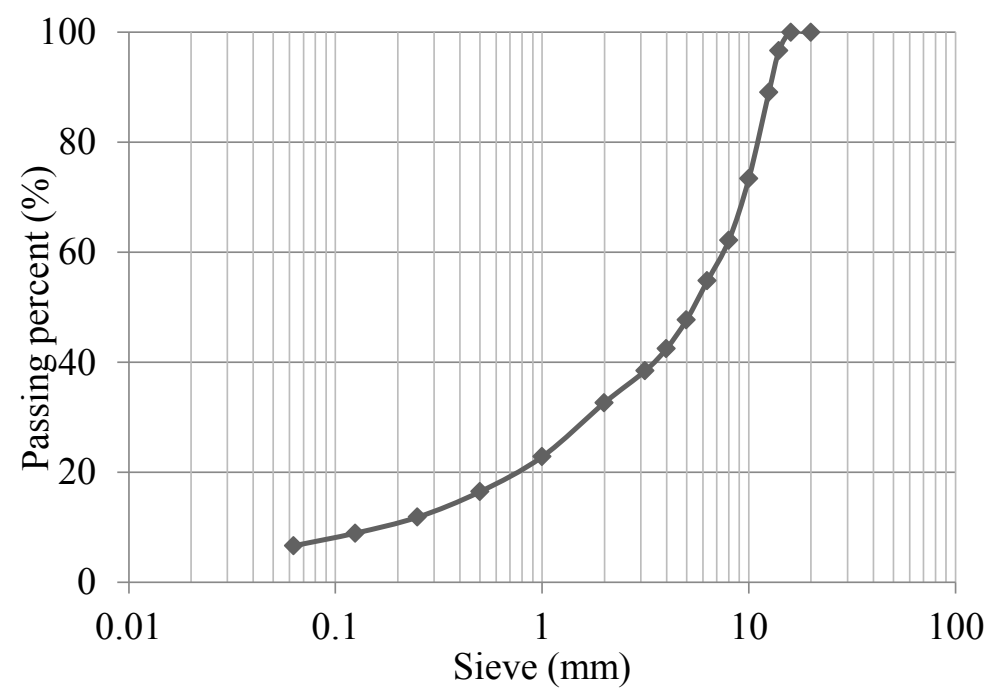

Figure 1: Grading curve of the aggregates

The test specimens used in CFTS and TSRST are cored in slabs of BBSG 0/14 that were compacted using the plate-compactor machine. Two series of cylindrical specimens are designed to comply with the geometry required by each test. Dimensions of the specimens used in CFTS are $80 \mathrm{~mm}$ in diameter $(\varnothing 80)$ and $120 \mathrm{~mm}$ in height. All these specimens (6 in total) are cored vertically from the same slab. For use in TSRST, 8 cylindrical specimens of diameter $50 \mathrm{~mm}(\varnothing 50)$ and of height $160 \mathrm{~mm}$ are core-drilled horizontally according to the European standard NF EN 12967-46. Porosity of every specimen is checked by means of the X-ray method [15], which is performed for both dry and partially saturated AC samples. Saturation of an AC specimen is obtained considering the following process: (i) a negative pressure of $-86 \mathrm{kPa}$ is applied during one hour to the initially dry specimen placed in a tank, 


\begin{tabular}{cccccc}
\hline $\begin{array}{c}\text { Type } \\
\text { of test }\end{array}$ & $\begin{array}{c}\text { Number of } \\
\text { specimens } \\
\text { tested }\end{array}$ & $\begin{array}{c}\text { Specimen } \\
\text { dimensions } \\
(\mathrm{mm})\end{array}$ & $\begin{array}{c}\text { Average } \\
\text { porosity } \\
(\%)\end{array}$ & $\begin{array}{c}\text { Average } \\
\text { degree of } \\
\text { saturation } \\
(\%)\end{array}$ & Test details \\
\hline CTFS & 6 & $\emptyset 80 \times 120$ & 6.2 & 63 & $\begin{array}{r}\text { All specimens are tested successively } \\
\text { under dry and wet conditions }\end{array}$ \\
\hline TSRST & 8 & $\emptyset 50 \times 160$ & 6.5 & 60 & $\begin{array}{r}3 \text { specimens are tested under dry } \\
\text { conditions and 5 under wet conditions }\end{array}$
\end{tabular}

92

(ii) water is slowly added until full immersion of the specimen then maintaining the negative pressure during three hours. For all the specimens tested, the degree of saturation determined by weight measurements is found to be around $60 \%$ (Table 1). 
The instrumented specimens are tested imposing traction-free boundary condition all over

106 their outer surface within a climatic chamber. The controlled temperature of the climatic chamber is varied from $10{ }^{\circ} \mathrm{C}$ to $-10{ }^{\circ} \mathrm{C}$ as shown in figure $2 \mathrm{~b}$. The specimens are tested first under dry conditions and then after partial saturation performed as explained before. The axial and radial strain evolutions are recorded during cooling of the AC samples which are free to deform given the mechanical boundary conditions.

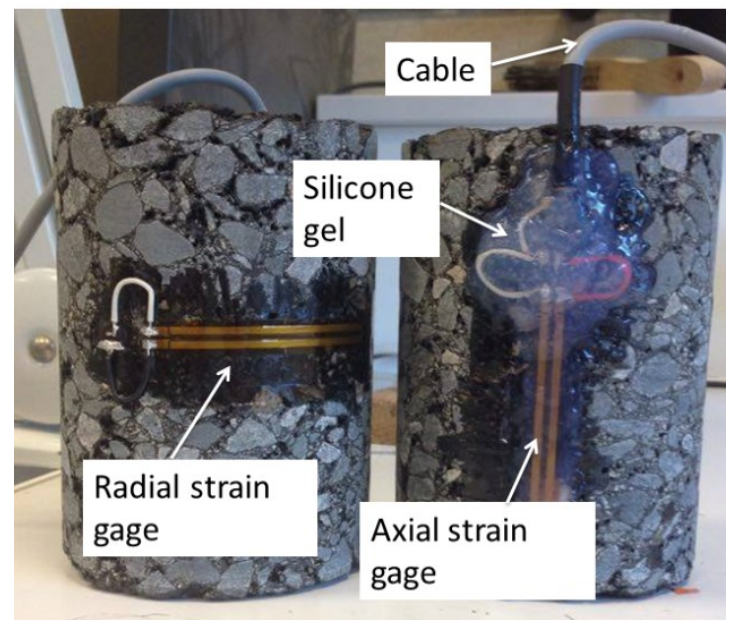

(a)

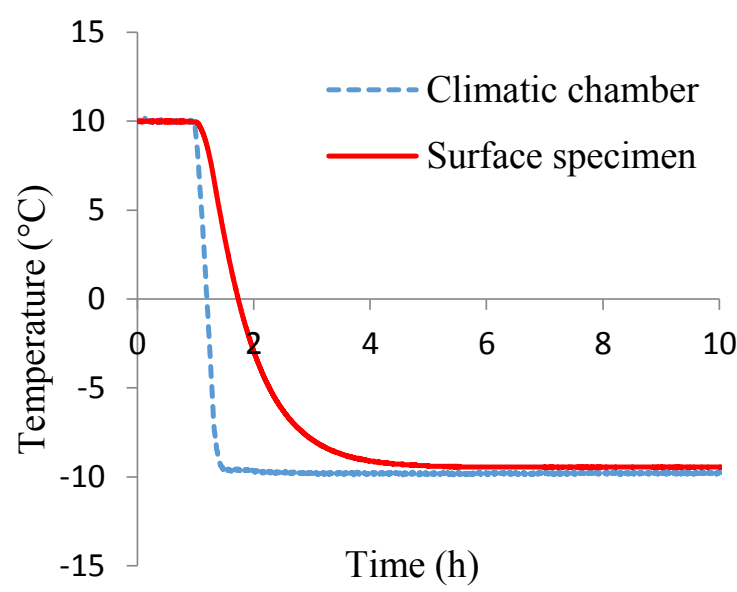

(b)

114 Figure 2: (a) Picture of the instrumented AC specimen. (b) Evolution of the controlled temperature of

115 the climatic chamber and of the temperature measured at the surface of a dry AC specimen during

116 CTFS testing.

118 Since strain gages are sensitive to temperature, their raw measurement must be corrected to

119 obtain the correct value of strain under variable temperature. In this study, the correction is 120 done based on the measurement of a particular gage glued on an invar rod also placed in the

121 climatic chamber and thus subjected to the same controlled temperature as the AC samples.

122 Invar is an alloy having a very small coefficient of thermal expansion 123 $\left(\alpha_{\text {Invar }} \approx 0.03 \mu \mathrm{m} / \mathrm{m} /{ }^{\circ} \mathrm{C}\right)$. 
125 The strain recorded on the AC sample can be decomposed into the following parts:

$$
\varepsilon_{A C}^{\text {measure }}(t)=\varepsilon_{A C}^{\text {true }}(t)+\varepsilon_{g a g e}^{\text {err }}(t)
$$

And that recorded on the Invar rod as follows:

$$
\varepsilon_{\text {Invar }}^{\text {measure }}(t)=\varepsilon_{\text {Invar }}^{\text {true }}(t)+\varepsilon_{\text {gage }}^{\text {err }}(t)
$$

Quantity $\varepsilon_{g a g e}^{e r r}(t)$ reflects the measurement bias brought by the gage sensitivity to temperature. However, considering that $\alpha_{\text {Invar }}$ is negligible then $\varepsilon_{\text {Invar }}^{\text {true }}(t)=\alpha_{\text {Invar }} \Delta \theta \sim 0$ and the actual (corrected) strain of AC samples is given by:

$$
\varepsilon_{A C}^{\text {true }}(t)=\varepsilon_{A C}^{\text {measure }}(t)-\varepsilon_{\text {Invar }}^{\text {measure }}(t)
$$

\section{Thermal stress restrained specimen test (TSRST)}

This test is adapted from the European standard NF EN 12967-46 (TSRST). The cylindrical specimens $(\varnothing 50 \times 160 \mathrm{~mm})$ tested are clamped between two press pistons and placed into a climatic chamber, the controlled temperature of which is decreased at the rate of $10{ }^{\circ} \mathrm{C} / \mathrm{h}$ (Fig $3 \mathrm{~b})$. The length of the specimen is maintained constant during the test by acting on the force imposed between the two pistons. The value of stress in the AC specimen is inferred from this force that ensures a zero longitudinal strain during testing. This is controlled through the corrected measurement (as described in the previous section) of a strain gage glued to the lateral surface of the AC specimens.

The TSRST campaign carried out in this study involves eight AC specimens among which three are tested under dry conditions and five after saturation. 
145

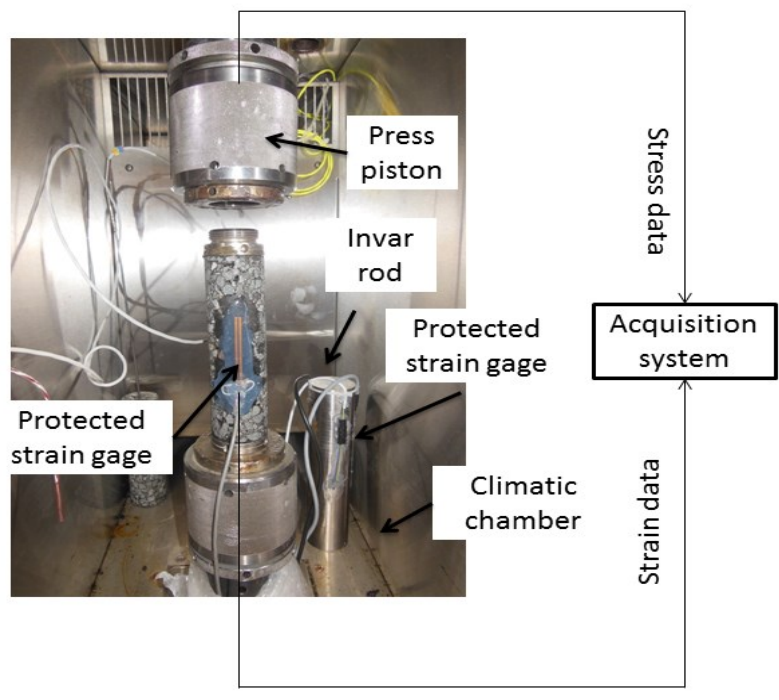

(a)

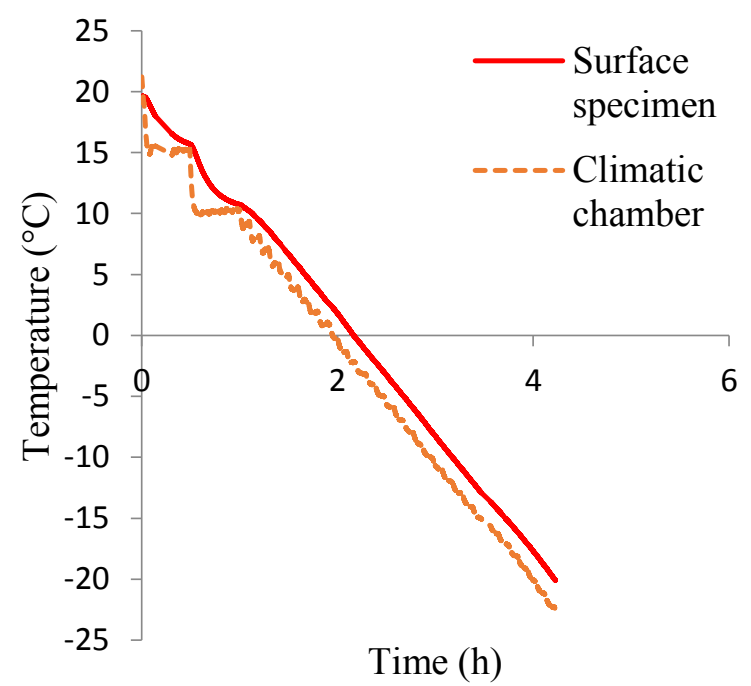

(b)

147 Figure 3: (a) Experimental set-up used in TSRST testing. (b) Evolution of the controlled temperature

148 of the climatic chamber and of the temperature measured by a sensor glued at the surface of an AC

149 specimen.

Note that to avoid variability effect from one sample to another in the comparison between the two tests considered in this paper, some saturated AC samples are utilized for both CTFS testing and then TSRST testing after the saturation has been set back to the initial level.

\section{Results and discussions}

157 Some typical experimental results from CTFS testing are presented below showing the corrected strain evolution with respect to time. In particular, figure 4 displays the comparison between the radial and the axial strain obtained for the same AC sample tested under dry and

160 wet conditions. The AC specimen under consideration has a porosity of $7.7 \%(n=7.7 \%)$ and 161 a degree of saturation equal to $65 \%\left(S_{r}=65 \%\right)$. 
As expected during cooling, the radial and the axial strain curves show an isotropic thermal contraction under dry condition. In this case, the change in strain for a temperature variation of $-20{ }^{\circ} \mathrm{C}\left(\Delta \theta=-20^{\circ} \mathrm{C}\right)$ is about $-500 \mu$ strain reflecting a coefficient of thermal expansion equal to $25 \mu \mathrm{m} / \mathrm{m} /{ }^{\circ} \mathrm{C}$, which is typical of $\mathrm{AC}$ materials.

Concerning the saturated specimen, the evolution of the axial and the radial strain is similar at the beginning to that obtained under dry condition. However, it exhibits for a while afterwards a "chaotic" phase composed of several peaks oriented opposite to the strain direction observed until that moment during cooling. Once this phase is over, the strain evolution becomes smooth again till the end of the test and is homothetic to the temperature curve whose decrease is ending at this time to eventually reach a plateau. During the "chaotic" phase, the evolution of the axial strain is not exactly similar to that of the radial strain but the two curves are superimposed again during the last part of the test.

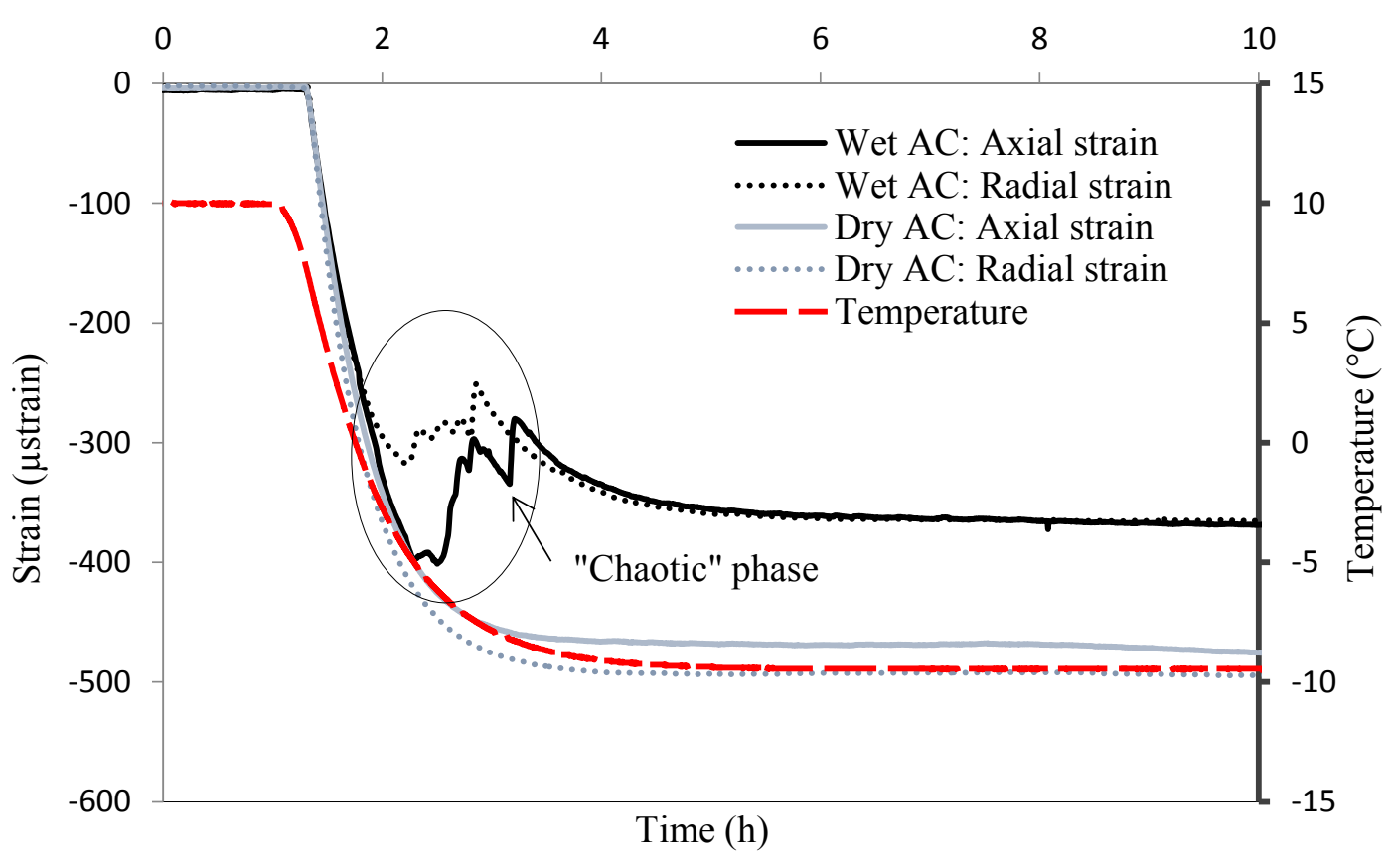

Figure 4: Corrected measurements of the axial and the radial strain recorded for an AC sample tested under dry and wet conditions ( $n=7.7 \%$ and $\left.S_{r}=65 \%\right)$ and temperature evolution measured on the outer surface of the dry specimen during CTFS testing. 
179 The comparison between the strain plateaus obtained for the dry and the wet specimens at the

180 end of the test at a temperature of $-10{ }^{\circ} \mathrm{C}$ shows a positive difference (swelling) of about $181130 \mu$ strain and $110 \mu$ strain in the radial and the axial direction, respectively. This difference 182 clearly results from the "chaotic phase" which undoubtedly can be associated to the water 183 phase change from liquid to ice within the whole sample. Indeed solidification is known to 184 induce an increase of $9 \%$ in volume in the case of free water. For the six tests of the CTFS 185 campaign, the swelling ("chaotic") phase starts as the external temperature is below $-2{ }^{\circ} \mathrm{C}$ instead of $0{ }^{\circ} \mathrm{C}$ probably due to several physical phenomena taking place in the AC samples.

187 These phenomena can be related to capillary forces, stagnancy of pore water and super 188 cooling effect, the chemical change of pore water at contact with the aggregates, etc.

189 Figure 5 shows a summary of the results obtained in this campaign. As displayed in figure 5a 190 on the left, the coefficients of thermal expansion calculated for the dry specimens in the axial and the radial directions can be considered similar; the relative difference between them is lower than $3 \%$. On the other hand, figure $5 \mathrm{~b}$ shows that the relative difference in terms of

193 swelling strain obtained in the two directions is also very small and of the order of $6 \%$.

194 Consequently, the behavior of the AC specimens (dry or saturated) can be assumed as 195 isotropic. 

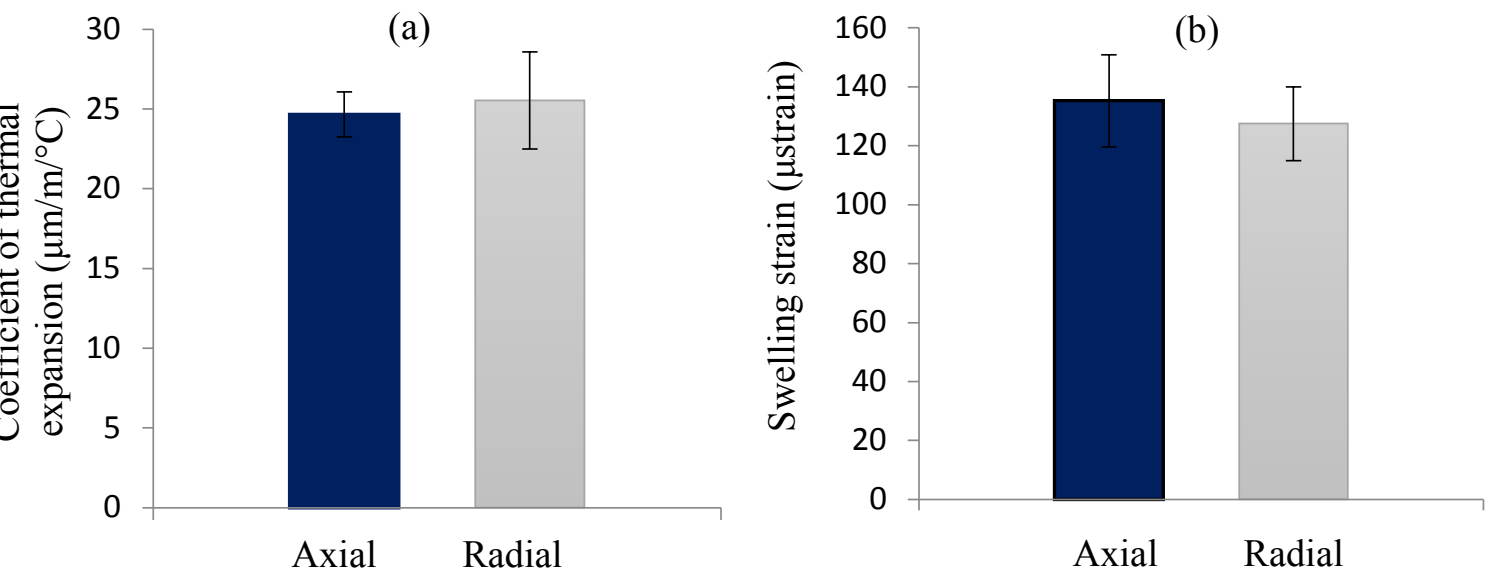

197 Figure 5: Comparison between the corrected measurements recorded in the axial and the radial

198 directions: (a) Coefficients of thermal expansion for the dry specimens. (b) Swelling strains in the case

199 of saturated specimens. (Error bars show the standard deviation of the measurements performed on 6

200 samples)

Representative results from TSRST testing are shown in figure 6a which displays the stress evolution obtained for dry and wet specimens when temperature is decreased from $20^{\circ} \mathrm{C}$ to $-30{ }^{\circ} \mathrm{C}$. The dry and the saturated $\mathrm{AC}$ samples have a porosity of $5.9 \%$ and $5.1 \%$, respectively. The saturated sample was first subjected to CTFS testing and then to TSRST

207 testing once saturation has been refilled to the initial level of $60 \%$. The swelling strain for the

208 saturated AC specimen is inferred from the difference between the final plateaus resulting from CTFS testing (Fig. 6b); a value of $150 \mu$ strain is obtained (axial direction). 
(a) TSRST

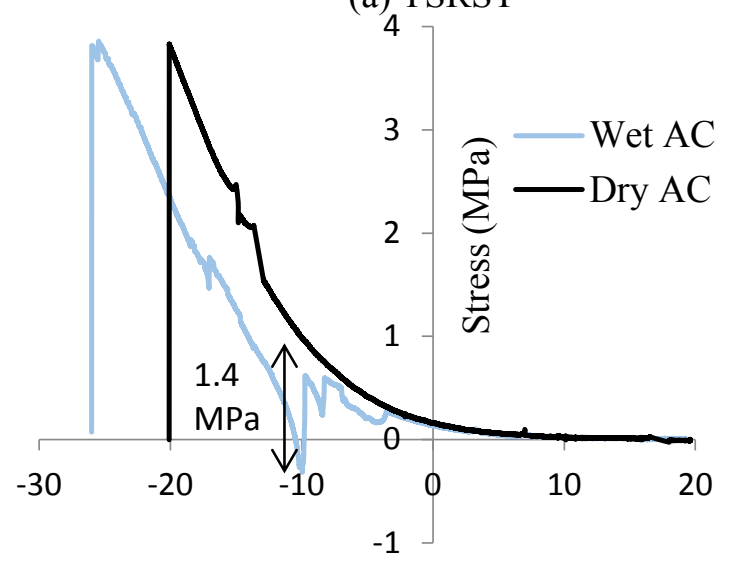

210

Temperature $\left({ }^{\circ} \mathrm{C}\right)$

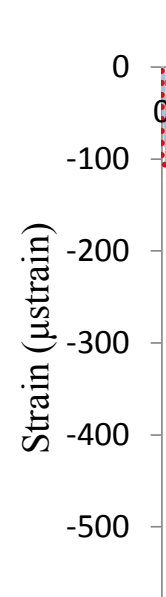

$-600$ (b) CTFS

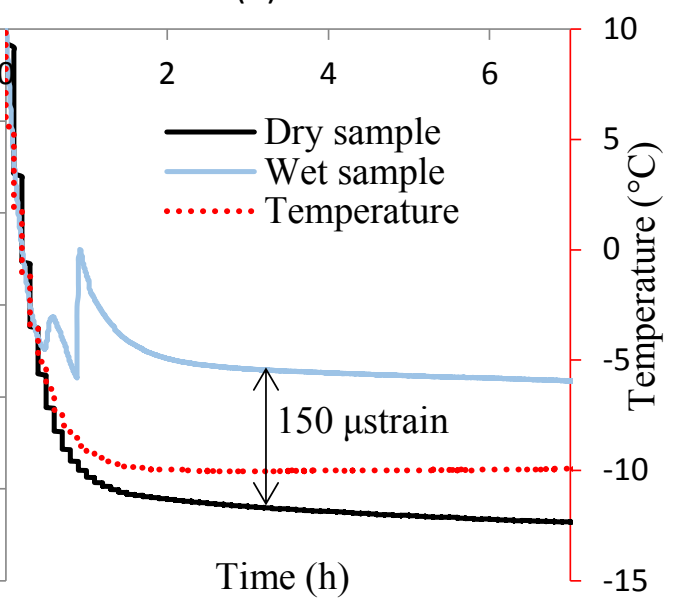

211 Figure 6: Comparison between the mechanical responses in terms of stress and strain obtained for the dry and wet AC samples: (a) TSRST, (b) CTFS

213 Concerning stress evolution, the dry AC sample exhibits the characteristic response of asphalt

214 concrete materials tested according to the TSRST protocol (Fig 6a); the axial tensile stress increases as temperature decreases to compensate thermal contraction. Due to hardening of the AC material with temperature (loss of relaxation capability), the tensile stress increases more and more as temperature diminishes. The tests stops brutally at failure of the specimen (i.e. $4 \mathrm{MPa}$ at $-21^{\circ} \mathrm{C}$ ), as illustrated by the drop of the stress curve in figure $6 \mathrm{a}$.

At the beginning of the test and as long as temperature is higher than the freezing point of pore water detected at around $-5^{\circ} \mathrm{C}$, the saturated sample exhibits a quite similar response as the dry sample. For temperature variations from $-5{ }^{\circ} \mathrm{C}$ to $-10{ }^{\circ} \mathrm{C}$, a decrease of the stress magnitude is then observed, even leading to slight compression at $-10{ }^{\circ} \mathrm{C}$. Afterward, the stress curve for the wet $\mathrm{AC}$ becomes similar again to that of the dry $\mathrm{AC}$, remaining parallel to it but below. Failure of the (partially) saturated specimen is reached for the same stress value as the dry specimen $(\approx 4 \mathrm{MPa})$ but at a lower temperature $\left(-26^{\circ} \mathrm{C}\right.$ instead of $\left.-21{ }^{\circ} \mathrm{C}\right)$. Basically, the shift between the two curves can be interpreted by a compressive stress of magnitude 1.4 $\mathrm{MPa}$ developing in the specimen during the phase change of water into ice. 
1.4 $\mathrm{MPa}$ "swelling stress" can be considered roughly as the counterbalance effect of the

$230150 \times 10^{-6}$ "swelling strain" through a secant modulus of $10,000 \mathrm{MPa}$ during the water

231 phase change.

232 The trend observed for this particular sample is confirmed by the rest of the TSRST 233 campaign. The average temperature at failure is lower for the saturated than for the dry 234 specimens. The values obtained are $-23 \pm 2.5^{\circ} \mathrm{C}$ and $-20.3 \pm 0.5^{\circ} \mathrm{C}$, respectively (Fig 7). On the other hand, the average critical stress value at material failure seems to be slightly higher for dry than for saturated specimens with values equal to $3.8 \pm 0.01 \mathrm{MPa}$ and $3.37 \pm 0.4 \mathrm{MPa}$, respectively (Fig 7).

However, note that the lower temperature obtained at failure for the saturated specimens must not be interpreted as an improvement of mechanical performance of the material in presence of water. TSRST test rather shows that a frost front propagating into saturated AC layers of pavements can develop unexpected internal stress field which effects need to be further investigated.

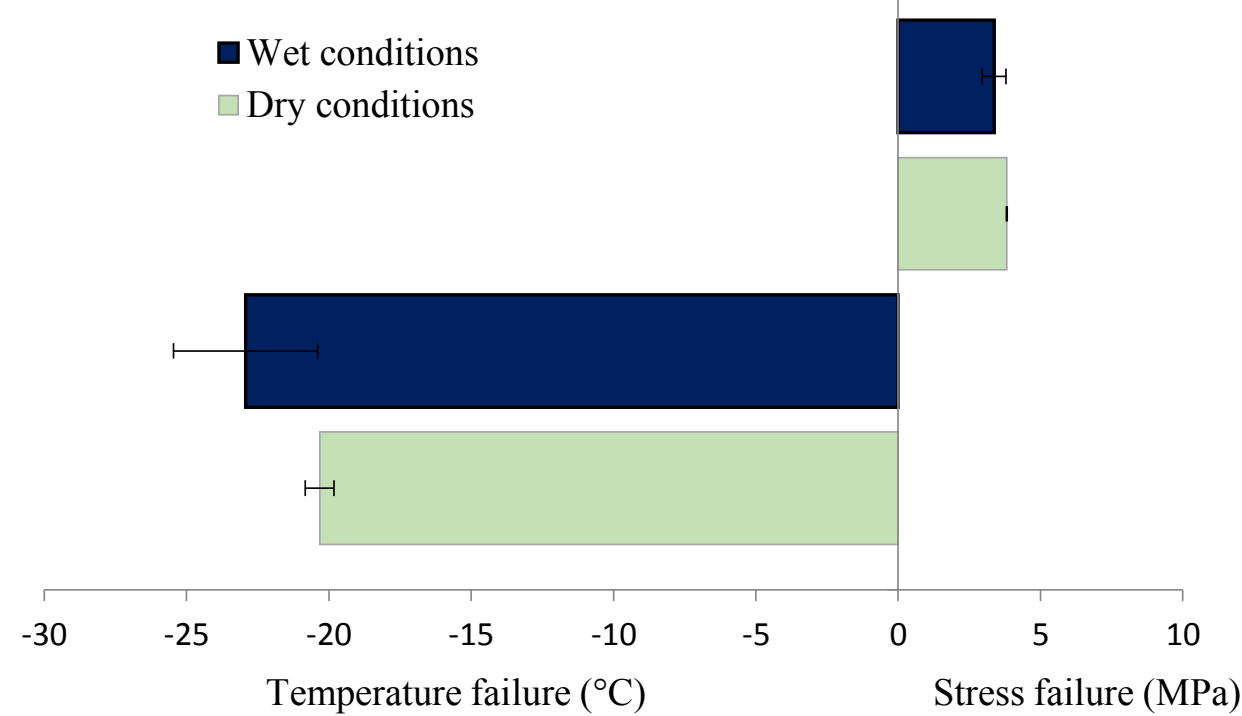

Figure 7: Comparison between the dry and the saturated $\mathrm{AC}$ specimens in terms of temperature and critical stress obtained at failure (averaged over all the samples of the TSRST campaign and error bars show the standard deviation of the measurements performed on 3 dry and 5 saturated samples). 
The impact of the phase change of pore water into ice on the creep function was studied in

$250[16]$ on the basis of complex modulus test campaigns performed on the same AC sample in

dry and saturated conditions. For temperatures above the freezing point of pore water no difference is observed between these two conditions, whereas ice formation is found to increase the stiffness of saturated AC specimens. However, the increase is less than $10 \%$ and is not considered in the following.

\section{CONSTITUTIVE MODEL DEDICATED TO THE BEHAVIOR OF SATURATED}

\section{AC EXPOSED TO FREEZING}

The experimental results presented earlier in this paper are used here to develop a constitutive law for the modeling of the thermo-mechanical behavior of partially saturated AC materials exposed to freezing. As well known, bituminous mixes are thermo-sensitive materials exhibiting viscoelastic properties which are accurately captured by the Huet model [17]. Consequently, the developed law is based on this model and extends its scope to taking into account variable temperature condition, thermal expansion and swelling effects due to phase change of pore water.

The development of the constitutive law is presented step-by-step in this section, going from the unidimensional behavior of $\mathrm{AC}$ under isothermal condition to the full tridimensional expression including all the aforementioned physical phenomena, especially frost effects. The developed constitutive law is then discretized in time and implemented in a numerical program. Finally this law is used to model the CTFS and the TSRST tests and is validated against the experimental data. 
272 The Huet model is a viscoelastic model composed of a linear elastic spring of modulus $E_{\infty}$

273 connected in series with two parabolic dashpots of exponent $k$ and $h$ (Fig 8). The creep

274 function for this model depends on time, $t$, and temperature, $\theta$, and reads:

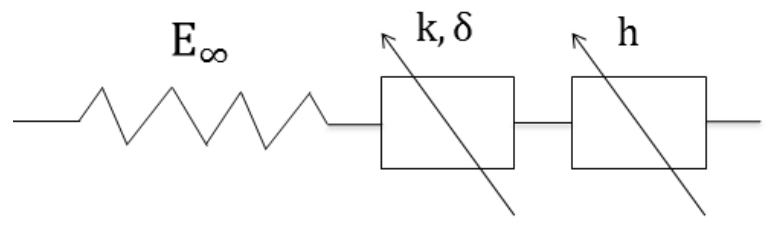

Figure 8: The Huet rheological model.

With

$$
J_{H}(t, \theta)=J_{h, k}\left(\frac{t}{a(\theta)}\right)
$$

in which $\Gamma(\cdot)$ stands for the gamma function and $\delta$ is a weight parameter associated to the dashpot of exponent $k$.

284 The creep function is written with respect to the single scalar variable $\frac{t}{a(\theta)}$ by virtue of the 285 time-temperature equivalence principle applying for asphalt materials. $a(\theta)$ denotes the timetemperature shift factor, which in this work is expressed as follows:

$$
a(\theta)=\exp \left(A_{0}+A_{1} \theta+A_{2} \theta^{2}\right)
$$

where $A_{0}, A_{1}$ and $A_{2}$ are constant parameters of the model. 
291 The Huet model parameters can be identified using experimental data stemming from

292 complex modulus tests performed in the frequency domain.

293 The constitutive law is then provided by the mathematical relationship below (of type Stieltjes

294 convolution integral), which expresses the strain response $(\varepsilon)$ to the stress history function $\sigma$ :

295

296

$$
\varepsilon(t)=J_{H}(t, \theta) \otimes \dot{\sigma}(t)=\int_{-\infty}^{\infty} J_{H}(t-\tau, \theta) \frac{d}{d t} \sigma(\tau) d \tau
$$

For an isotropic material, the above constitutive equation (Eq. 7) can be extended to the tridimensional case by considering the deviatoric and the volumetric components of strain and stress tensors and introducing the creep function for each of them. In this paper, Poisson's ratio is assumed real and constant leading to the following Hooke type constitutive relationship:

304

305

$\boldsymbol{\varepsilon}(t)=J_{H}(t, \theta) \otimes[(1+v) \dot{\boldsymbol{\sigma}}(t)-v \operatorname{tr}(\dot{\boldsymbol{\sigma}}(t)) \boldsymbol{I}]=\int_{0}^{t} J_{H}(t-\tau, \theta) \frac{d}{d t}[(1+v) \dot{\boldsymbol{\sigma}}(\tau)-$

$306 v \operatorname{tr}(\dot{\boldsymbol{\sigma}}(\tau)) \boldsymbol{I}] d \tau$ 
310 Temperature variation has two significant effects to be considered on the behavior of dry 311 asphalt materials: (i) thermal expansion, (ii) change of creep function. Considering the case of 312 saturated AC material, a third effect due to swelling has to be added as shown by the 313 experimental findings presented before.

The thermal expansion is accounted for through the classical relationship:

$$
\varepsilon^{t h}(\theta)=\alpha \Delta \theta \boldsymbol{I}
$$

in which $\alpha$ is the coefficient of thermal expansion $\left(\mu \mathrm{m} / \mathrm{m} /{ }^{\circ} \mathrm{C}\right)$ and $\Delta \theta(t)=\theta(t)-\theta_{o}$ is the difference between the temperature at time $\mathrm{t}$ and that of the reference state denoted $\theta_{o}$. On the other hand, the computation of the mechanical strain under variable temperature can be achieved using the concept of "equivalent time" defined by [18]:

$$
t_{e}(t)=\int_{0}^{t} \frac{d \tau}{a(\theta(\tau))}
$$

This expression can be easily derived for a Kelvin-Voigt model which viscosity is proportional to $a(\theta)$. Using the time $t_{e}$ instead of $\mathrm{t}$ makes it possible to express this model as a Kelvin Voigt constitutive law but with constant viscosity and independently of the temperature. This property extends to the Huet model using the spectral decomposition of its creep function as an infinite series of Kelvin Voigt elements which viscosity depends for all of them upon the same $a(\theta)$ function.

Considering only on the mechanical strain, the Stieltjes integral then writes: 


$$
\boldsymbol{\varepsilon}\left(t_{e}\right)=\int_{0}^{t_{e}} J_{h, k}\left(t_{e}-\tau_{e}\right)\left[(1+v) \frac{\boldsymbol{d} \boldsymbol{\sigma}}{\boldsymbol{d} t_{e}}\left(\tau_{e}\right)-v \operatorname{tr} \frac{\boldsymbol{d} \boldsymbol{d}}{\boldsymbol{d} t_{e}}\left(\tau_{e}\right) \boldsymbol{I}\right] d \tau_{e}
$$

That is, coming back to time $t$ and taking also the thermal strain part, the viscoelastic law under variable temperature:

$$
\boldsymbol{\varepsilon}(t)=\int_{0}^{t} J_{h, k}\left(t_{e}(t)-t_{e}(\tau)\right)[(1+v) \dot{\boldsymbol{\sigma}}(\tau)-v \operatorname{tr} \dot{\boldsymbol{\sigma}}(\tau) \boldsymbol{I}] d \tau+\boldsymbol{\varepsilon}^{t h}(\theta(t))
$$

\section{Model for the case of partially saturated AC material}

In addition to thermal expansion and change in the creep (resp. relaxation) capability and as evidenced by the experimental tests presented in section 2, saturated AC exhibits swelling effects when temperature is varied passing through the freezing point of pore water.

With regards to CTFS test, here we suggest to model the swelling effects by adding a strain component $\boldsymbol{\varepsilon}_{f}$ to the constitutive law (Eq. 12). This one is assumed isotropic and depending on the difference between the temperature of the material and that of the freezing point of pore water $\theta_{f}$. As already mentioned, $\theta_{f}$ may depend on several physical phenomena taking place in the porous asphalt and not considered in the model. From the macroscopic point of view of the present approach, $\theta_{f}$ is set according to the temperature at which the behavior of the saturated AC sample departs from that of the dry sample in the experimental tests. Thus, the swelling strain is defined as:

$$
\boldsymbol{\varepsilon}_{f}(\theta(t))=\varepsilon_{f 0} \frac{1-\tanh \left[m\left(\theta(t)-\theta_{f}\right)\right]}{2} \boldsymbol{I}
$$

where $m$ is a parameter that allows us to adjust the temperature range (centered in $\theta_{f}$ ) for which most of the swelling deformation occurs (Figure 9). This parameter is used to calibrate the transition of $\varepsilon_{f}$ from zero prior to freezing to $\varepsilon_{f 0}$ after full completion of the phase change of pore water. Depending on the value of $m$, this transition can go from quite smooth to sharp. 


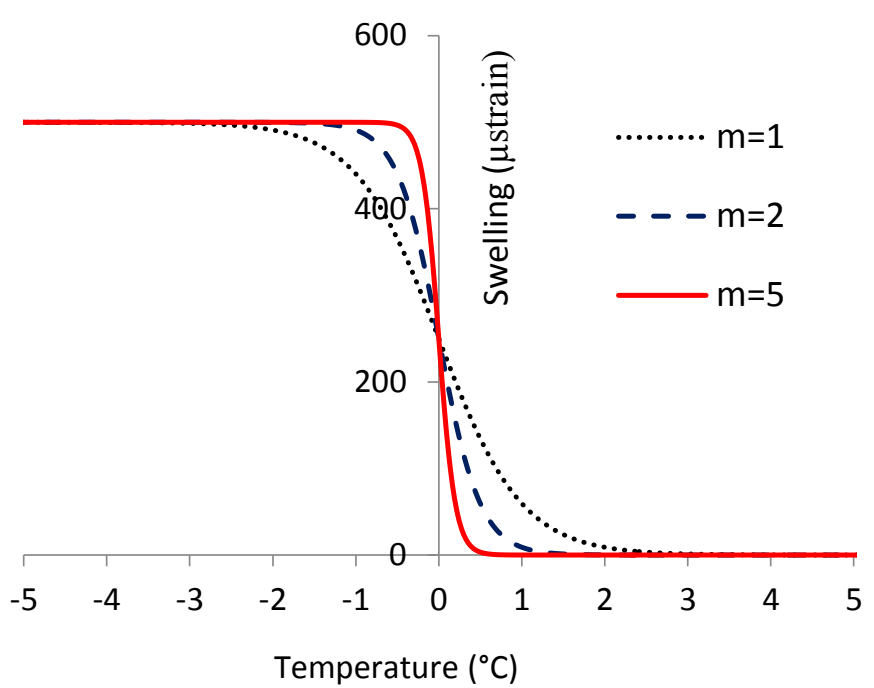

Figure 9: Swelling strain as a function of temperature for different values of parameter $m$ and $355 \theta_{f}=0{ }^{\circ} \mathrm{C}$

357 Finally, the constitutive law developed to represent the thermo-mechanical behavior of AC 358 partially saturated with water can be schematized by the rheological model shown in figure

359 10. Considering a constant Poisson's ratio, the three dimensional expression of this law (for 360 variable temperature) is given by:

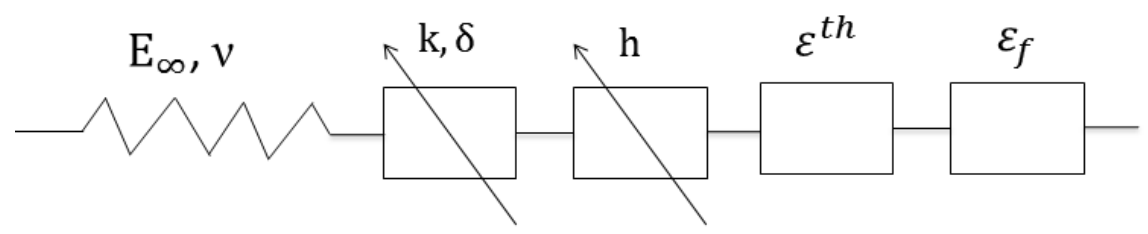

364 Figure 10: Sketch of the rheological model developed to model saturated AC materials. 


\section{Time discretization of the three-dimensional constitutive law}

367 As shown by Eq. (14) the developed constitutive law is complex and its use requires

368 numerical computation. In this section, we present the time discretization of this law for 369 isothermal and variable temperature conditions. For both cases, expression of the strain tensor

370 at time $t_{n}$ for a given stress history function is derived as well as the dual expression of the 371 stress tensor in response to a given strain history function.

\section{Constitutive law in isothermal condition}

373

Under this condition, the $\theta$ variable is omitted in the following equations. Using the Euler method and considering the time interval $\left[t_{i}, t_{i+1}\right]$, we approximate the time derivative of the stress tensor in Eq. (12) by the following finite difference: $\dot{\boldsymbol{\sigma}}(\mathrm{t}) \approx \frac{\sigma_{\mathrm{i}+1}-\sigma_{\mathrm{i}}}{\Delta \mathrm{t}}$, where $\Delta t=$ $t_{i+1}-t_{i}$ is the time step assumed constant. At first, we focus on the assessment of $\varepsilon\left(t_{n}\right)$ at the different times $t_{0}, t_{1}, \ldots, t_{i}, \ldots t_{N}$ resulting from the following implicit calculation of Eq. (12):

$$
\boldsymbol{\varepsilon}\left(t_{n}\right) \approx \sum_{i=0}^{n-1} \int_{t_{i}}^{t_{i+1}} J_{H}\left(t_{n}-\tau\right) d \tau \frac{(1+v)\left[\boldsymbol{\sigma}_{i+1}-\boldsymbol{\sigma}_{i}\right]-v \operatorname{tr}\left(\boldsymbol{\sigma}_{i+1}-\boldsymbol{\sigma}_{i}\right) \boldsymbol{I}}{\Delta t}
$$

Here we assume that at step $n$ all strain and stress quantities $\boldsymbol{\varepsilon}_{\mathrm{i}}, \boldsymbol{\sigma}_{\mathrm{i}}$ for $0 \leq i \leq n-1$ have already been computed and are known.

The definite integral of the creep function at each time step is computed according to the trapezoidal rule, which for only one interval between $t_{i}$ and $t_{i+1}$ leads to:

$$
\boldsymbol{\varepsilon}\left(t_{n}\right) \approx \sum_{i=0}^{n-1} \frac{J_{H}\left(t_{n}-t_{i+1}\right)+J_{H}\left(t_{n}-t_{i}\right)}{2} \Delta t \times \frac{(1+v)\left[\boldsymbol{\sigma}_{i+1}-\boldsymbol{\sigma}_{i}\right]-v \operatorname{tr}\left(\boldsymbol{\sigma}_{i+1}-\boldsymbol{\sigma}_{i}\right) \boldsymbol{I}}{\Delta t}
$$


385 For the sake of simplification, we denote by $\bar{\chi}$ the tensor of all the known values from $t_{0}$ to $t_{n-1}$ related to history of the stress tensor. $\bar{\chi}$ is defined by:

387

$\bar{\chi}=J_{H_{n, n}}\left[(1+v) \boldsymbol{\sigma}\left(t_{n-1}\right)-v \operatorname{tr}\left(\boldsymbol{\sigma}\left(t_{n-1}\right)\right) \boldsymbol{I}\right]-\sum_{i=0}^{n-2} J_{H, i+1}\left[\left[(1+v) \boldsymbol{\sigma}\left(t_{i+1}\right)-\right.\right.$

$\left.\left.v \operatorname{tr} \boldsymbol{\sigma}\left(t_{i+1}\right) \boldsymbol{I}\right]-\left[(1+v) \boldsymbol{\sigma}\left(t_{i}\right)-v \operatorname{tr} \boldsymbol{\sigma}\left(t_{i}\right) \boldsymbol{I}\right]\right]$

390

391

in which:

$$
J_{H, i+1}=\frac{J_{H}\left(t_{n}-t_{i+1}\right)+J_{H}\left(t_{n}-t_{i}\right)}{2}
$$

Using this notation, Eq. (17) simply reads:

$$
\boldsymbol{\varepsilon}\left(t_{n}\right)=J_{H_{n, n}}\left[(1+v) \boldsymbol{\sigma}\left(t_{n}\right)-v \operatorname{tr}\left(\boldsymbol{\sigma}\left(t_{n}\right)\right) \boldsymbol{I}\right]-\bar{\chi}
$$

395

401 With:

$$
\lambda_{n}=\frac{v}{(1-2 v)(1+v) J_{H_{n, n}}}, \text { and } \mu_{n}=\frac{1}{2(1+v) J_{H_{n, n}}}
$$

the expression of the stress tensor at the time $t_{n}$ is finally given by: 


$$
\boldsymbol{\sigma}\left(t_{n}\right)=2 \mu_{n} \boldsymbol{\varepsilon}\left(t_{n}\right)+\lambda_{n} \operatorname{tr} \boldsymbol{\varepsilon}\left(t_{n}\right) \boldsymbol{I}+2 \mu_{n} \bar{\chi}+\lambda_{n} \operatorname{tr} \overline{\boldsymbol{\chi}} \boldsymbol{I}
$$

406

407 This equation at time $t_{n}$ is similar to Hooke's law with "initial" stress.

408

In the case of a partially saturated AC subjected to variable temperature condition the

411 constitutive law is given by Eq (14). Its discretized expression is derived in a similar way as that of the isothermal case adding the concept of equivalent time, thermal expansion and the swelling strain. The discretized form at time $t_{n}$ reads:

415 where the quantities

$$
\tilde{J}_{H, i+1}=\frac{J_{H}\left(t_{e}\left(t_{n}\right)-t_{e}\left(t_{i+1}\right)\right)+J_{H}\left(t_{e}\left(t_{n}\right)-t_{e}\left(t_{i}\right)\right)}{2}
$$

are now computed considering the equivalent time evaluated as:

$$
t_{e}\left(t_{n}\right)=\int_{0}^{t_{n}} \frac{d \tau}{a(\theta(\tau))}=\sum_{i=0}^{n-1} \frac{\Delta t}{2}\left[\frac{1}{a\left(\theta\left(t_{i+1}\right)\right)}+\frac{1}{a\left(\theta\left(t_{i}\right)\right)}\right]
$$

419 The tensor $\bar{\chi}^{\prime}$ refers to quantities evaluated for past times (from $t_{0}$ to $t_{n-1}$ ) and is given by:

$$
\bar{\chi}^{\prime}=\tilde{J}_{H_{n, n}}\left[(1+v) \boldsymbol{\sigma}\left(t_{n-1}\right)-v \operatorname{tr}\left(\boldsymbol{\sigma}\left(t_{n-1}\right)\right) \boldsymbol{I}\right]-\sum_{i=0}^{n-2} \tilde{J}_{H_{n, i+1}}\left[\left[(1+v) \boldsymbol{\sigma}\left(t_{i+1}\right)-\right.\right.
$$

423 The thermal expansion and freezing strain at time $t_{n}$ are computed using the following expressions: 


$$
\boldsymbol{\varepsilon}^{t h}\left(\theta\left(t_{n}\right)\right)=\alpha\left(\theta\left(t_{n}\right)-\theta\left(t_{0}\right)\right) \boldsymbol{I}
$$

426 and

$$
\boldsymbol{\varepsilon}_{f}\left(\theta\left(t_{n}\right)\right)=\varepsilon_{f 0} \frac{1-\tanh \left[m\left(\theta\left(t_{n}\right)-\theta_{f}\right)\right]}{2} \boldsymbol{I}
$$

428

$\boldsymbol{\varepsilon}\left(t_{n}\right)$ can be computed from Eq. (24) when $\boldsymbol{\sigma}\left(t_{n}\right)$ is given. Conversely, Eq. (30) provides the stress tensor at time $t_{n}$ as a function of strain and quantities related to the loading history of the material:

$$
\boldsymbol{\sigma}\left(t_{n}\right)=2 \tilde{\mu}_{n} \boldsymbol{\varepsilon}\left(t_{n}\right)+\tilde{\lambda}_{n} \operatorname{tr}\left(\boldsymbol{\varepsilon}\left(t_{n}\right)\right) \boldsymbol{I}+\mathbf{Y}_{n}
$$

With

$$
\boldsymbol{r}_{n}=2 \tilde{\mu}_{n}\left[\bar{\chi}^{\prime}-\boldsymbol{\varepsilon}^{t h}\left(\theta\left(t_{n}\right)\right)-\boldsymbol{\varepsilon}_{f}\left(\theta\left(t_{n}\right)\right)\right]+\tilde{\lambda}_{n} \boldsymbol{t r}\left[\bar{\chi}^{\prime}-\boldsymbol{\varepsilon}^{\boldsymbol{t h}}\left(\boldsymbol{\theta}\left(\boldsymbol{t}_{\boldsymbol{n}}\right)\right)-\boldsymbol{\varepsilon}_{\boldsymbol{f}}\left(\boldsymbol{\theta}\left(\boldsymbol{t}_{\boldsymbol{n}}\right)\right)\right] \boldsymbol{I}
$$

and

$$
\tilde{\lambda}_{n}=\frac{v}{(1-2 v)(1+v) \tilde{J}_{n, n}}, \text { and } \quad \tilde{\mu}_{n}=\frac{1}{2(1+v) \tilde{J}_{n, n}}
$$

Eq (30) also reads like Hooke's law with “initial” stress $\boldsymbol{\Upsilon}_{n}$.

The equations above are implemented in a numerical program. Figure 11 shows the different steps of the algorithm utilized to compute the whole set of strain and stress tensor components in response to the given ones considering variable temperature, thermal expansion and swelling strain. The developed program is used in the next section to model the behavior of dry and saturated AC during CTFS and TSRST testing. 


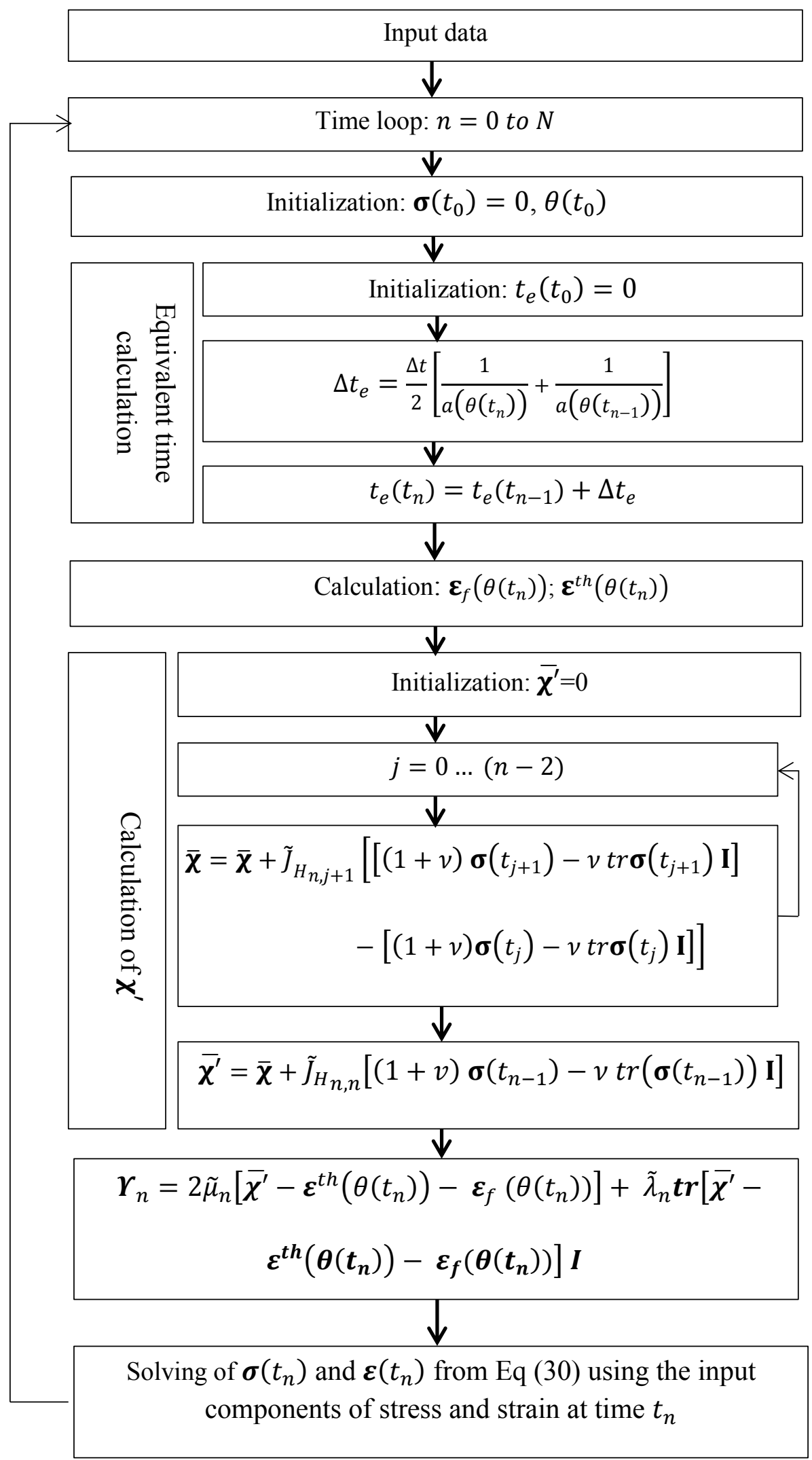

447 Figure 11: Algorithm for evaluation of the constitutive law under variable temperature 


\section{MODELING OF CTFS AND TSRST WITH THE DEVELOPED CONSTITUTIVE} LAW

The developed constitutive relationship can be used now to simulate the transient response of AC samples in the CTFS and TSRST tests, assuming homogeneous temperature, strain and stress within the samples over the all duration of the tests. The numerical results are compared with the experimental data presented in section 2 obtained with the same specimen submitted to the two tests. The viscoelastic properties of the AC material are characterized from complex modulus tests [19] for the dry AC sample and the use of software Viscoanalyse to determine the Huet parameters. The values obtained are shown in Table 2. Poisson's ratio is set to 0.28 . The other material parameters related to thermal expansion and freezing are inferred from the CTFS and TSRST testing (Table 2).

The input temperature for the simulations is that measured by the sensor placed at the surface of the dry specimen.

\begin{tabular}{ccc} 
Huet model parameters & $\begin{array}{c}\text { Thermal expansion } \\
\text { coefficient } \\
\left(\mu \mathrm{m} / \mathrm{m} /{ }^{\circ} \mathrm{C}\right)\end{array}$ & \multicolumn{2}{c}{ Swelling strain coefficients } \\
\hline$E_{\infty}=34862 \mathrm{MPa} ; h=0.57 ;$ & $\alpha=25$ & $-6{ }^{\circ} \mathrm{C}$ for $\mathrm{CTFS}$ and $\theta_{f}=-10^{\circ} \mathrm{C}$ for \\
$k=0.21 ; \delta=1.96 ; v=0.28$ & &
\end{tabular}




\section{CTFS test modeling}

In this test, stress free boundary condition applies on the outer surface of the specimen $\boldsymbol{\sigma}(t)=0$. The components of the strain tensor in cylindrical coordinates check: $\varepsilon_{r r}(t)=\varepsilon_{\theta \theta}(t)=\varepsilon_{z Z}(t)$ and $\varepsilon_{r z}(t)=\varepsilon_{r \theta}(t)=0$.

Figure 12 shows the computed strain for the dry and saturated conditions as well as the comparison with the experimental data. The model accuracy for the dry condition is satisfying; a thermal expansion coefficient of $25 \mu \operatorname{strain} /{ }^{\circ} \mathrm{C}$ leading to a thermal strain approximately equal to $500 \mu$ strain for $\Delta \theta=-20^{\circ} \mathrm{C}$. On the other hand, the numerical curve obtained for the saturated condition exhibits globally a similar evolution as the experimental curve. However, in accordance to the modeling approach considered here only one single peak is observed during the phase change time period. The model performs relatively well though, when $\varepsilon_{f 0}$ is determined as the difference of strain between the plateaus obtained for the dry and the saturated conditions at the end of testing.

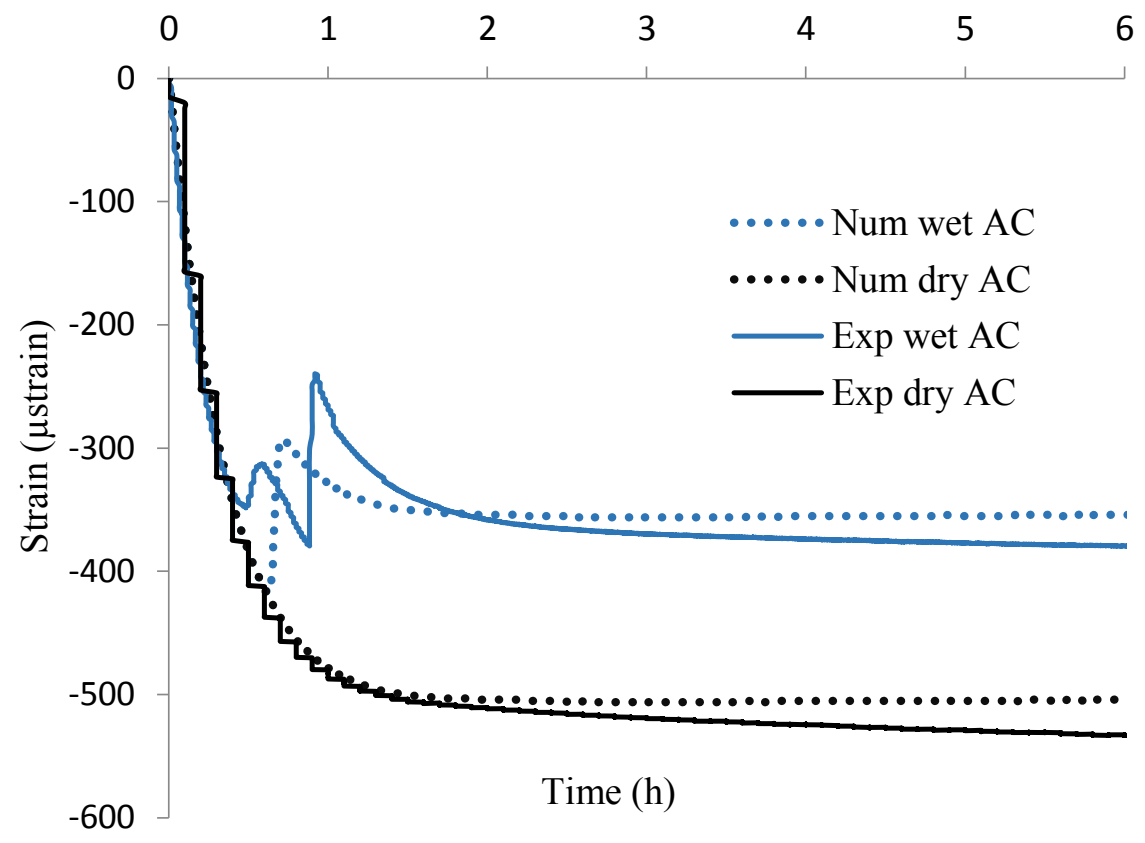

Figure 12: Comparison between the numerical results and experimental data obtained for CTFS under dry and wet conditions. 


\section{TSRST test modeling}

482

483

484

485

486

487

488

489

490

491

492

493

494

495

496

497

498

In that case, the two unknowns are the axial stress $\sigma_{z z}(t)$ due to the force applied by the piston to ensure zero deformation of the specimen in the axial direction and the resulting radial strain $\varepsilon_{r r}(t)$. The other strain and stress components are assumed zero.

Figure 13 shows the comparison between the curves of experimental and computed axial stress obtained for dry and wet conditions. Obviously the specimen rupture observed at the end of the test (Figure 6a) cannot be reproduced since not accounted for in the model. In the simulations, $\varepsilon_{f 0}$ is set to zero and $150 \mu$ strain (according to CTFS testing results) for the dry and saturated conditions, respectively. As shown in Figure 13, a good agreement is obtained for the dry condition revealing the relevance of the concept of equivalent time. The results obtained for the saturated case are also fairly good overall. As long as temperature is greater than $\theta_{f}=-10^{\circ} \mathrm{C}$, the stress evolution is superimposed with that of the dry AC. For temperature around $\theta_{f}$, the axial stress shows an abrupt decrease and even enter the compressive domain. This phase coincides in the model with the occurrence of the peak due to $\varepsilon_{f}$. This drop in the axial stress is well captured by the model as the counterpart of the swelling effect modeled through $\varepsilon_{f}$. Afterwards the curve evolves similarly again to that of the dry specimen but is shifted due to the drop undergone at freezing. 


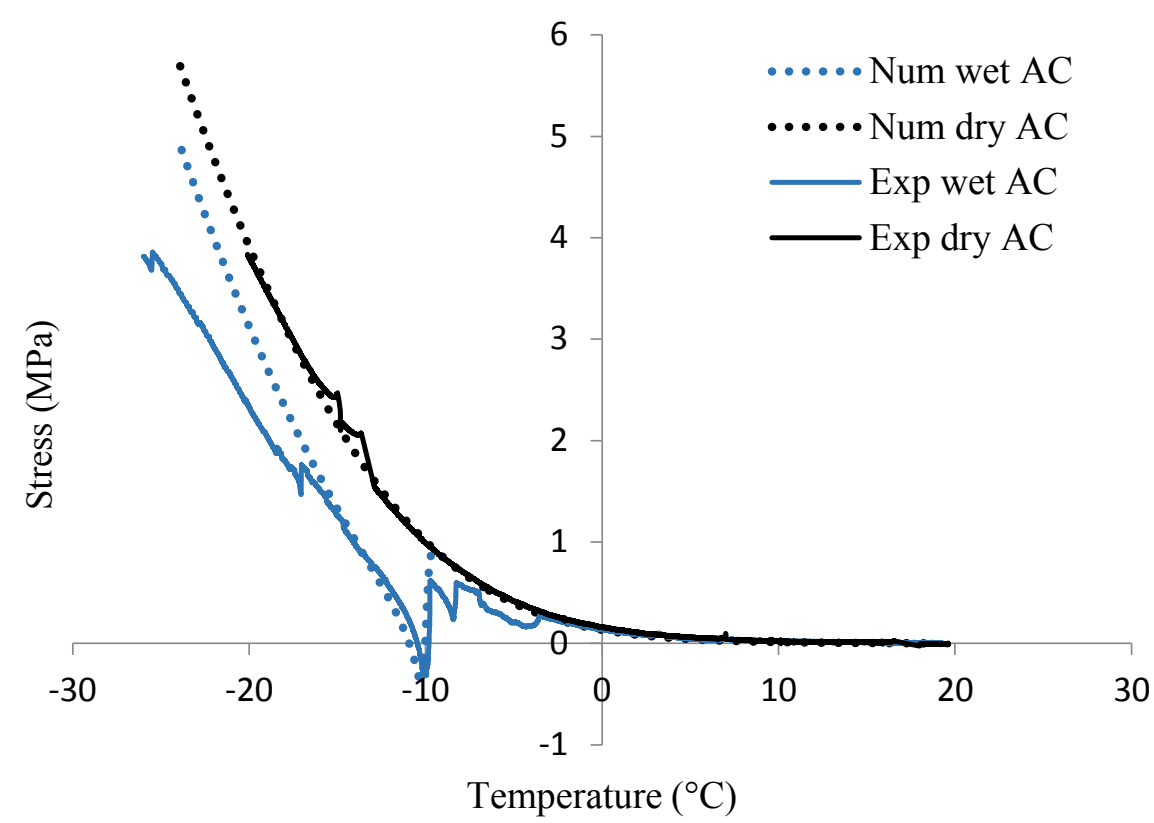

499

Figure 13: Comparison between TSRST experimental data and the simulated axial stress obtained for the dry and partially saturated conditions

Finally, the agreement of the simulations with the experimental data is fairly good for both tests what validates the developed model incorporating thermal expansion and swelling strain and relying on the concept of equivalent time. It is shown that the calibration of the swelling strain can be performed according to CTFS testing once full solidification of pore water has taken place. Then the model makes it possible to simulate accurately the complex evolution of the axial stress observed during TSRST testing of the saturated AC specimens.

\section{CONCLUSION}

510 The purpose of the present research was to study the thermo-mechanical behavior of partially

511 saturated asphalt concrete (AC) materials subjected to freezing. This research program was

512 initiated following the sudden damaging of asphalt pavements observed during recent winters

513 in France and Northern Europe countries. 
514 Two types of experimental tests were carried out in this study; CTFS and TSRST testing were

515 performed on dry and partially saturated samples to evaluate the impact of freezing pore water 516 on the behavior of saturated AC. The test results have revealed a significant effect with 517 prominent and brutal changes of the mechanical response in terms of strain (swelling) or 518 stress of the specimens tested. In addition, these tests have indicated that deformation due to 519 thermal expansion and swelling was quite isotropic. Concerning TSRST testing, the 520 (negative) temperature at which failure occurs was found to be $12 \%$ lower for the saturated specimens than for the dry ones. In that case, the critical stress at failure was also slightly smaller.

In parallel, a tridimensional constitutive model dedicated to saturated AC materials was developed on the basis of experimental results. The development of this model has taken into account the following characteristics of AC: viscoelasticity, thermal expansion and swelling effect under variable temperature. Discretization of this law was implemented in a numerical program and was validated through simulation of the CTFS and TSRST testing.

It is believed that the significant frost effects observed during CTFS and TSRST transposed to a pavement structure could lead to the issue mentioned above. Further steps in this research

530 will thus include testing on pavement structures and implementation of the developed constitutive law in a finite element (FE) code coupling the mechanical problem to the heat equation with phase change. These simulations will be used to investigate the impact of swelling and self-stress effects developing at the frost front.

\section{ACKNOWLEDGMENT} this work. Experimental tests in the laboratory were carried out at IFSTTAR Nantes. 


\section{REFERENCES}

[1] Vulcano- GN, Kerzreho JP, Mauduit V, and Chabot A, "Stripping phenomenon of top layers of thick pavements," presented at the 11th International Conference on Asphalt Pavements, France, 2010.

[2] V. Mauduit et al., "Dégradation subite des enrobés bitumineux par période de gel/dégel: Analyse de cas de terrain et recherche exploratoire en laboratoire," Bull. Lab. Ponts Chaussées, no. 279, p. pp-47, 2013.

[3] C. Mauduit, F. Hammoum, J.-M. Piau, V. Mauduit, S. Ludwig, and D. Hamon, "Quantifying expansion effects induced by Freeze-Thaw cycles in partially water saturated bituminous mix: Laboratory Experiments,” Road Mater. Pavement Des., vol. 11, no. sup1, pp. 443-457, 2010.

[4] S. Lamothe, D. Perraton, and H. Di Benedetto, "Contraction and expansion of partially saturated hot mix asphalt samples exposed to freeze-thaw cycles," Road Mater. Pavement Des., vol. 16, no. 2, pp. 277-299, 2015.

[5] S.Caro, E.Masad, A.Bhasin, and D.N.Little, "Moisture susceptibility of asphalt mixtures part 1: Mechanisms,” Int. J. Pavement Eng., vol. 9, no. 2, pp. 81-98, Apr. 2008.

[6] S.Caro, E.Masad, A.Bhasin, and D.N.Little, "Moisture susceptibility of asphalt mixtures part 2: Characterisation and modeling," Int. J. Pavement Eng., vol. 9, no. 2, pp. 99-114, 2008.

[7] R. Roberson and J. Siekmeier, "Determining material moisture characteristics for pavement drainage and mechanistic empirical design," Res. Bull. Minn. Dep. Transp. Off. Mater. Road Res., 2002.

[8] X. Chen and B. Huang, "Evaluation of moisture damage in hot mix asphalt using simple performance and superpave indirect tensile tests," Constr. Build. Mater., vol. 22, no. 9, pp. 1950-1962, 2008.

[9] E. Özgan and S. Serin, "Investigation of certain engineering characteristics of asphalt concrete exposed to freeze-thaw cycles," Cold Reg. Sci. Technol., vol. 85, pp. 131-136, 2013. 
[10] W. Si, B. Ma, N. Li, J. Ren, and H. Wang, "Reliability-based assessment of deteriorating performance to asphalt pavement under freeze-thaw cycles in cold regions," Constr. Build. Mater., vol. 68, pp. 572-579, 2014.

[11] H. Xu, W. Guo, and Y. Tan, "Permeability of asphalt mixtures exposed to freeze-thaw cycles," Cold Reg. Sci. Technol., vol. 123, pp. 99-106, Mar. 2016.

[12] H. Xu, W. Guo, and Y. Tan, "Internal structure evolution of asphalt mixtures during freeze-thaw cycles," Mater. Des., vol. 86, pp. 436-446, 2015.

[13] S. Lamothe, D. Perraton, and H. D. Benedetto, "Degradation of hot mix asphalt samples subjected to freeze-thaw cycles and partially saturated with water or brine," Road Mater. Pavement Des., vol. 18, no. 4, pp. 849-864, Jul. 2017.

[14] "NF EN 13108-1 - Mélanges bitumineux - Spécifications des matériaux - Partie 1: enrobés bitumineux.” AFNOR, 2008.

[15] “NF P98-250-5, Essais relatifs aux chaussées - Préparation des mélanges hydrocarbonés - Partie 5: mesure en laboratoire de la masse volumique apparente d'un corps d'épreuve au banc gammadensimétrique.” AFNOR, March-1993.

[16] C. Mauduit et al., "Experimental investigation of frost/thaw effects on bituminous mixes under wet conditions," in Asphalt Pavements, CRC Press, 2014, pp. 139-146.

[17] C.Huet, "Etude par méthode d'impédance du comportement viscoélastique des matériaux hydrocarbonés," Université de Paris, 1963.

[18] Heck JV, "Modélisation des déformations réversibles et permanentes des enrobés bitumineux Application à l'ornièrage des chaussées," Thèse, Université de Nantes, 2001.

[19] “NF EN 12697-26 - Mélanges bitumineux - Méthodes d'essai pour mélange hydrocarboné à chaud - Partie 26 : module de rigidité.” AFNOR, Jun-2012. 